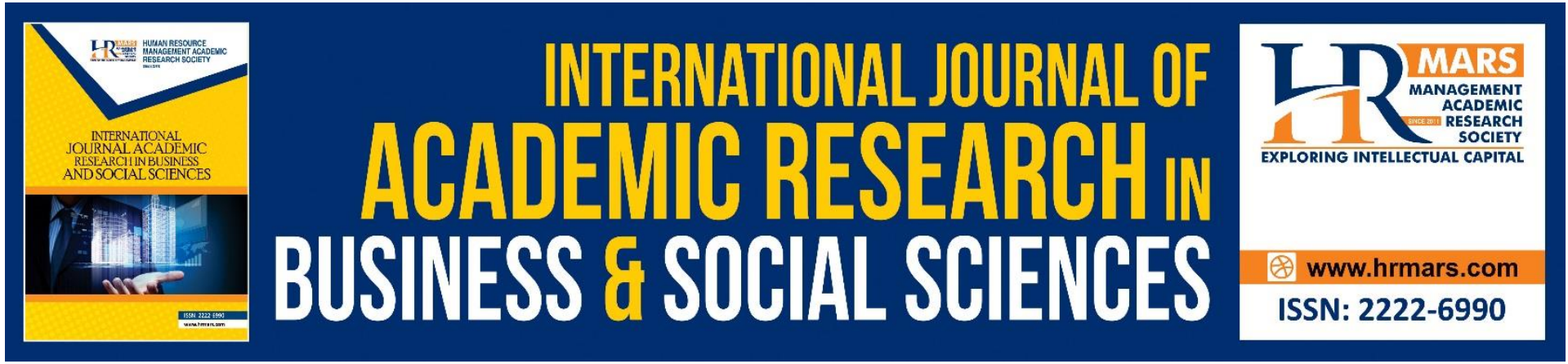

\title{
An Analysis of Co-movement in Equity Sector Indices
}

\section{Aminah Shari, Fauziah Mahat}

To Link this Article: http://dx.doi.org/10.6007/IJARBSS/v11-i9/11059

DOI:10.6007/IJARBSS/v11-i9/11059

Received: 05 July 2021, Revised: 28 July 2021, Accepted: 20 August 2021

Published Online: 11 September 2021

In-Text Citation: (Shari \& Mahat, 2021)

To Cite this Article: Shari, A., \& Mahat, F. (2021). An Analysis of Co-movement in Equity Sector Indices. International Journal of Academic Research in Business and Social Sciences, 11(9), 696-705.

Copyright: (C) 2021 The Author(s)

Published by Human Resource Management Academic Research Society (www.hrmars.com)

This article is published under the Creative Commons Attribution (CC BY 4.0) license. Anyone may reproduce, distribute, translate and create derivative works of this article (for both commercial and non-commercial purposes), subject to full attribution to the original publication and authors. The full terms of this license may be seen at: http://creativecommons.org/licences/by/4.0/legalcode

Vol. 11, No. 9, 2021, Pg. 696 - 705

http://hrmars.com/index.php/pages/detail/IJARBSS

JOURNAL HOMEPAGE

Full Terms \& Conditions of access and use can be found at http://hrmars.com/index.php/pages/detail/publication-ethics 


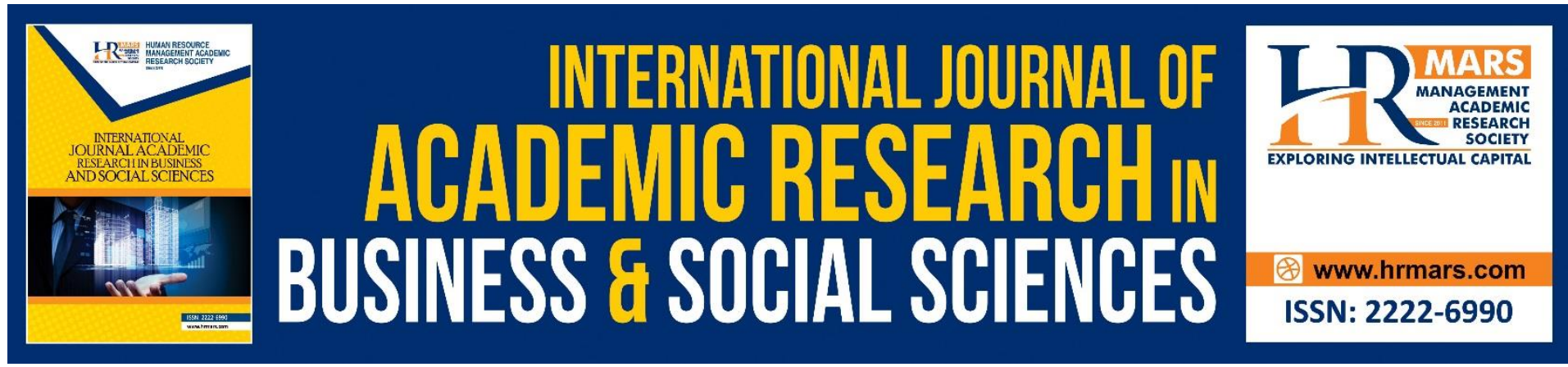

\title{
An Analysis of Co-movement in Equity Sector Indices
}

\author{
Aminah Shari \\ Labuan Faculty of International Finance, Universiti Malaysia Sabah Kampus Antarabangsa \\ Labuan, 87000 Federal Territory of Labuan, Labuan
}

Fauziah Mahat

Department of Accounting and Finance, School of Business and Economics, Universiti Putra Malaysia, 43400 UPM, Serdang Selangor

\begin{abstract}
This study examines the co-movement among equity sector returns of the Malaysian capital market. The relationship is investigated using Correlation-based on Ordinary Least Square (OLS) and Multivariate-GARCH Dynamic Conditional Correlation (DCC) to examines the volatilities and correlations of sectoral equity indexes. The study uses daily data that ranges from 5 February 1999 to 6 February 2019. The OLS result reveal that there is a strong comovement between sectoral equity and the stock market prices except in tin and mining sector. While time-varying correlations among sectoral indexes are estimated using MGARCHDCC, the empirical results from this analysis show that the plantation, properties and tin and mining sectors have negative unconditional correlation with the stock market, which is a good sign of diversification advantages. The findings have important implications helping portfolio managers and investors to understand the co-movement of equity sectors and then formulate policy measures that encourage better portfolio diversification.
\end{abstract}

Keywords: Co-Movement, Equity, Multivariate GARCH, Volatility, Investment

\section{Introduction}

The co-movement of returns risks in the equity markets has impacted effective portfolio diversification (Marfatia, 2017). In particular, the co-movement of risk has been the main issue among investors, regulators, and academic researchers. Also, it is important to distinguish the time horizon of investment due to the risk differences among short-term and long-term investments for the planning of investment strategies and portfolio diversification strategy (Candelon, Piplack, \& Straetmans, 2008).

Literature review on the co-movement of equity market returns has to go through dynamic changes over time can be found, for instance in (Bekaert \& Harvey, 1995). One of the limitations observed from this literature is that it does not differentiate the co-movement of risks based on investment horizons. Thus, Barun (2015) argued that the diversification of risk is possible when there is a difference in investment horizons. A few previous research 
documented the stock market's co-movement based on their time-domain but not on the integration frequency domain. Those studies that undertook a time-frequency domain approach into the analysis are mainly limited to the returns level (Bouri, Gupta, Hosseini, \& Lau, 2018; Kim \& Sun, 2017; Mazouz, Mohamed, \& Saadouni, 2016).

Researchers who have assessed the volatility linkages across the market have measured the linkages' level through historical volatility measure (Ahmad, Mishra, \& Daly, 2018; Mensi et al., 2017). They have used GARCH as the basis for the framework measure, but the measure cannot capture the investor's expectation of future equity market volatility. Thus, some scholars have introduced different volatility transmission measures to capture a dimension of investor's predictability. Investor's predictability is a multidimensional phenomenon; recently, Bouri et al. (2018) paid attention to the implied volatility indices. However, the measure does not capture the portfolio diversification implication as they measure the intermarket (Bouri et al., 2018).

The article is organized as follows. Section 2 briefly review the relevant literature on comovement. Section 3 elaborates the methodology and data. Section 4 presents empirical results and discussion. Section 5 covers conclusion and policy recommendations.

\section{Literature Review}

The importance of portfolio weighted in developing a well-diversified asset allocation can be seen from the study by Aliu et al. (2017), which examined the risk and return trade-off of the automotive industry. The study used a correlation-based method to test the portfolio optimization theory through investment in the same industry. The research found that investment in the same sector did not provide risk diversification, but the investors still benefited from risk and return trade-off. Mohamed Dahir, Mahat, Ab Razak, and Bany-Ariffin (2018) investigated the correlation between exchange rates and stock returns using wavelet analysis. Their findings suggested that the exchange rates correlate positively with conventional stock returns.

Jiang, $\mathrm{Yu}$ and Hashmi (2017) compared the impact of the global financial crises on conventional equity indexes of the six countries, namely China, Hong Kong, Japan, Germany, UK, and the USA, using the vector auto-regression (VAR) model and the Granger causality test for a sample of equity indices from 2007 to 2009. The findings showed that the financial crisis was negatively associated with the global equity market; that is, the global equity market returns decreased as the financial crisis increased. This pattern suggests that the general comovements of global stock markets slowly adjust their co-movement level while the potential loss of their earning is remarkably high in some economies.

Using a sample of conventional stocks measured by Nikkei 225 of Japan, Strait Times Index of Singapore, Hang Seng Index of Hong Kong, and Shanghai Composite Index of China, Sun and $\mathrm{Xu}$ (2018) provided evidence of co-movement in weekly Asian financial market stock returns by investigating time-varying correlations and lead-lag relationship in returns over the period 2000-2013. Using the Coherence Morlet Wavelet analysis, the results showed a strong comovement between the stocks indices headquartered in the same geographical location in the long-term level. The same work also showed that the co-movement during a financial crisis was unstable in various time scales. Greenwood (2008) studied the relations between 
overweighting and the co-movement of a Nikkei 225 stock index with other stocks in the index using ordinary least square regression as the analysis method in Japan for a sample of 1458 Japanese stock from 1993 to 2003. His findings showed that index overweighting had a positive and negative association with co-movement; that is, the positive relationship between index overweighting and co-movement as the index increased overweighting among stocks in the Nikkei index. On the other hand, index overweighting had an antagonistic relationship as the index decreased overweighting among stocks outside of the Nikkei index.

Al-yahyaee et al (2020) used the CAPM-EGARCH model and the wavelet analysis to test 20 types of sectoral indices of Islamic and conventional in the US stock exchange covering the basic material, consumer services, consumer goods, energy, financial, healthcare, industries, technology, telecommunication, and utilities; they found several significant findings. Firstly, the results illustrated a strong positive correlation between various sectoral indices. In contrast, the most significant co-movements of returns over time and across investment horizons were technology, telecommunications, basic materials, and consumer goods sectors. It was found that both Islamic and conventional assets sectors of consumer goods, energy, financial, healthcare, and telecommunications sectors offered portfolio diversification benefits during all sample periods.

\section{Methodology of Research}

In this section, the study implements the correlation-based on Ordinary Least Square (OLS) and MGARCH-DCC. For this objective, the study investigated the daily co-movement between sectoral assets return and the composite index. Specifically, the study investigated the comovement of sectoral equity of consumer, construction, finance, industrial, industrial product, plantation, properties, tin and mining and trade and services. The study began the analysis by considering the correlation-based model to test the inter-asset relationship among the variables of interest following the conventions of Christoffersen et al (2014); Dimic et al (2016); Cho et al (2016). Next, following the investigation of the co-movement patterns between equity sectors and their changes over time using the model to capture the dynamic relationship between equity sectors.

\section{Correlation-based Analysis}

The study began the analysis by considering the correlation-based model to test the interasset relationship among the variables of interest following the conventions of Christoffersen et al (2014); Dimic et al (2016); Cho et al (2016). The first equation represents the timevariation in correlation on the set of variables identified in the previous literature. The study first described the data sets used and briefly discussed the univariate model. The daily stock return was calculated as the natural logarithm of the price index relative. Subsequently, the study measured the dispersion in correlations across pairs of assets at each point in time and check whether this dispersion has changed over time. The equity sector return was computed as the first difference of the logarithm of daily indexes times 100. In other words, the formula for equity sector returns can be written as follows:

$\mathrm{R}=100 \times \log \left(\mathrm{P}_{\mathrm{t}} /\left(\mathrm{P}_{\mathrm{t}-1}\right)\right)$

(1) 
Where $R_{t}$ indicates the stock returns and $\mathrm{P}$ represents stock index levels at the time $(t)$ and $(\mathrm{t}-1)$.

The study investigated the relationship between equity returns and composite index using correlation-based on Ordinary Least Square (OLS). The analysis was used to test the interasset relationship among the capital market. In order to see how the cross-correlation trends change with time. The correlation coefficient is defined as:

\author{
$\rho_{i k}=$ covariance $(i, k)$ \\ standard deviation $i \times$ standard deviation $k$
}

(2)

$$
\rho_{i k}=\frac{\sigma_{i k}}{\sigma_{i} \sigma_{k}}
$$

\title{
MGARCH-DCC
}

The empirical analysis started with the investigation of the co-movement patterns between equity sectors and composite index and their changes over time. GARCH analysis can be used to detect stylized facts of financial time series namely volatility clustering and fat tails. It has been applied to volatility modelling. In addition, the Multivariate Generalized Autoregressive Conditional Heteroskedasticity (MGARCH) model is widely used for portfolio optimization, pricing of assets and derivatives, computation of the value at risk (VaR), futures hedging, volatility transmitting and asset allocation (Minovi \& Simeunovi, 2002).

Engle (2002) develops the dynamic conditional correlation (DCC)-GARCH model, which offers flexibility to simultaneously model the multivariate conditional volatility of stock returns and their time-varying correlations. The DCC is a multivariate GARCH model in which correlation are time-varying according to autoregressive specification. Engle (2002) develop two-step namely estimation of univariate GARCH model for each series and dynamic conditional correlations from standardized residuals.

$H_{t}=D_{t} R_{t} D_{t}$

(3)

In equation $2, H_{t}$ is the $\mathrm{n} \times \mathrm{n}$ conditional covariance matrix, $R_{t}$ is the dynamic correlation matrix and $D_{t}$ is a diagonal matrix with time- varying standard deviations.

$D_{t}=\operatorname{diag}(\mathrm{h} 111 / 2, \ldots \mathrm{hkkt1} / 2)$

Rt $=\operatorname{diag}(q 11 \mathrm{t}-1 / 2 \ldots \ldots . . q k k t-1 / 2)$ Qt diag $(q 11 t-1 / 2 \ldots \ldots . q k k t-1 / 2)$

where $Q_{t}$ is a symmetric positive definite matrix:

$Q_{t}=\left(1-\theta_{1}-\theta_{2}\right) \bar{Q}+\theta_{1} \varepsilon_{t-1} \varepsilon_{t-1}+\theta_{2} \theta_{t-1}$

(4)

$\bar{Q}$ is the $n \times n$ unconditional correlation matrix of the standardized residuals $\varepsilon_{i t}$. The parameters $\theta_{1}$ and $\theta_{2}$ are non-negative with a sum of less than unity. The study calculate the conditional correlation at time $t$ as:

$\rho_{i j, t}=\frac{q_{i j, t}}{\sqrt{q_{i i, t} q_{j j, t}}}, \forall \mathrm{i}, \mathrm{j}=1, \ldots \ldots \ldots, \mathrm{n}, \mathrm{i} \neq \mathrm{j}$

(5) 
The Quasi-Maximum Likelihood Estimation (QMLE) is used to estimate the model. This rich conditional correlation parameterization allows examining the co-movement of one market with each other market and inferring how the dependence evolves over time. As a result, the least correlated stock indices would offer better diversification benefit to investors.

\section{Data}

The data used in this study consists of sectoral equity indices and stock market index. The paper uses daily data that ranges from 5 February 1999 to 6 February 2019 extracted from Thomson Reuters DataStream. The sectors breakdown is according to the Securities Commission of Malaysia classification. The sample sectors consist of consumer product (LCONP), construction (LCONS), finance (LFIN), industrial (LIND), industrial product (LINDP), plantations (LPLNT), properties (LPRO), tin and mining (LTNM) and trade and services (LTNS). In addition, the used of sector portfolios would minimize the impact of any survivorship bias or look-ahead bias. In addition, sector portfolios are useful in this context because of the wide variability in business cycles and risk properties across the firms over these sectors (Faff, Hillier \& Hillier, 2000). The study used the daily frequency data due to following reasons, first, more complete information on the dynamic conditional correlation than the monthly data. More specifically, using the daily frequency data is more useful for investors to build an optimal portfolio and generate economic gains. On the other hand, Mensi, Hammoudeh, and Kang (2017) document that a daily data model is a better predictor of returns than a monthly data model.

\section{Empirical Results}

In this section, the study analyzed the unconditional correlation between equity sectors return and stock market index by calculating the linear correlation coefficient. Then, the computation of cross-asset correlations using DCC-MGARCH followed. The correlation coefficient between the change in asset price and the change in equity index was computed. The correlation results explained the degree of co-movement between two variables. The value of correlation ranged between -1 and +1 , where -1 means perfect negative correlation and +1 means perfect positive correlation.

Table 1. Descriptive Statistics of sectoral indices

\begin{tabular}{lcccccc}
\hline & Mean & Std. Dev. & Skewness & Kurtosis & Jarque-Bera & Observations \\
\hline KLCl & 0.007 & 0.353 & -0.659 & 14.277 & $27356.990^{* * *}$ & 5093.000 \\
LCONP & 0.012 & 0.283 & -0.583 & 12.959 & $21334.080^{* * *}$ & 5093.000 \\
LCONS & -0.003 & 0.563 & -1.093 & 19.397 & $58071.370 * * *$ & 5093.000 \\
LFIN & 0.009 & 0.409 & -0.390 & 13.465 & $23369.250^{* * *}$ & 5093.000 \\
LIND & 0.008 & 0.349 & -0.422 & 14.750 & $29450.150 * * *$ & 5093.000 \\
LINDP & 0.006 & 0.377 & -0.789 & 13.300 & $23043.220 * * *$ & 5093.000 \\
LPLNT & 0.013 & 0.426 & -0.357 & 18.804 & $53108.020 * * *$ & 5093.000 \\
LPRO & -0.001 & 0.467 & -0.566 & 14.835 & $29996.540 * * *$ & 5093.000 \\
LTNM & 0.010 & 1.136 & 2.057 & 67.571 & $888369.200^{* * *}$ & 5093.000 \\
LTNS & 0.005 & 0.382 & -0.518 & 14.660 & $29078.530 * * *$ & 5093.000 \\
\hline
\end{tabular}

Statistical significance at ${ }^{*} p<0.05,{ }^{* *} p<0.01$, and ${ }^{* * *} p<0.001$

Standard deviations (std. dev.) 
Table 1 shows the descriptive statistics of returns for sectoral indices and market return. With regard to sectoral indices, it appears that the volatility represented by the standard deviation is the highest for tin and mining sector and the lowest volatility for the consumer product. The average daily returns are relatively small than standard deviation, but the technology sector indicated the lowest average returns and highest volatility among the selected sectors. The skewness was negative for all selected sectors except in tin and mining sector. The finding in line with previous study of Mensah and Premaratne (2017) which found the banking sector negatively skewed. As a result, based on Jarque-Bera statistic, the study rejected the null hypothesis demonstrating that the data were normally distributed in all series.

\section{Correlation Analysis}

The relationship between equity returns and composite index is investigated using correlation-based on Ordinary Least Square (OLS). The paper uses daily data in the period of 1999 to 2019. The OLS result indicated that majority of sectoral equity have higher correlation with the composite index except in tin and mining sector as shown in Table 2.

Table 2. Correlation Matrix Analysis

\begin{tabular}{lllllllllll}
\hline & KLCI & LCONP & LCONS & LFIN & LIND & LINDP & LPLNT & LPRO & LTNM & LTNS \\
\hline KLCI & 1 & & & & & & & & & \\
LCONP & 0.721 & 1 & & & & & & & & \\
LCONS & 0.722 & 0.571 & 1 & & & & & & & \\
LFIN & 0.894 & 0.633 & 0.674 & 1 & & & & & & \\
LIND & 0.803 & 0.698 & 0.588 & 0.658 & 1 & & & & & \\
LINDP & 0.775 & 0.643 & 0.677 & 0.696 & 0.701 & 1 & & & & \\
LPLNT & 0.688 & 0.534 & 0.530 & 0.566 & 0.572 & 0.563 & 1 & & & \\
LPRO & 0.712 & 0.623 & 0.726 & 0.691 & 0.586 & 0.733 & 0.545 & 1 & & \\
LTNM & 0.243 & 0.244 & 0.256 & 0.239 & 0.206 & 0.268 & 0.205 & 0.290 & 1 & \\
LTNS & 0.938 & 0.648 & 0.688 & 0.788 & 0.783 & 0.727 & 0.592 & 0.704 & 0.240 & 1 \\
\hline
\end{tabular}

\section{The Estimated Conditional Volatilities of Equity Sector Return and Composite Index}

Figure 1 illustrates the time-varying properties of conditional volatilities of the equity sectors return with the Malaysian composite index. The figure shows that the consumer product sector has the lowest volatility whereas the tin and mining sector have the highest volatility. The equity sectors return and composite index follow the same trend, with composite index moving closely together except in tin and mining sector. The tin and mining sector are affected by the financial crisis while other equity sectors are less affected. The other equity sector could be a better option in terms of portfolio diversification for investors in equity markets because of its low volatility.

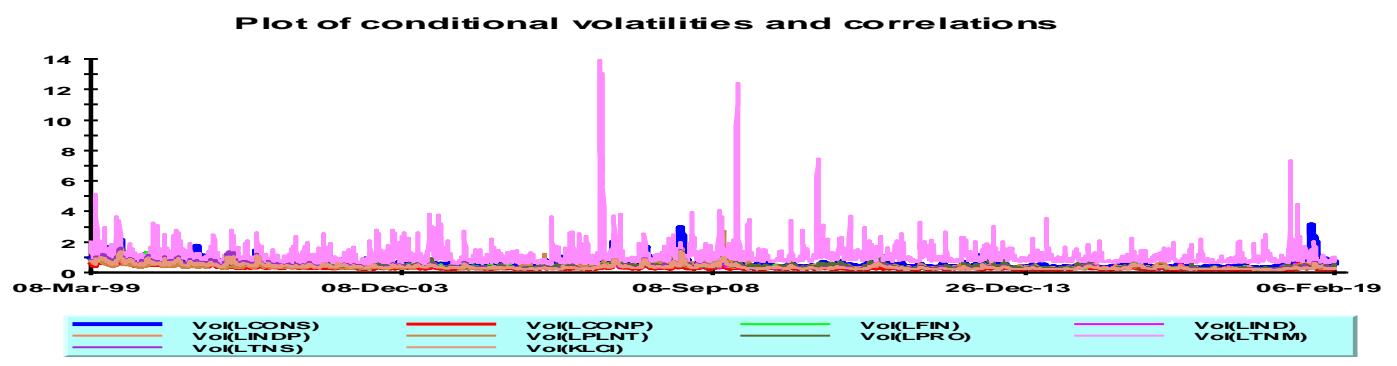

Figure 1. Conditional volatilities of Malaysian equity sector return and composite index 


\section{The Estimated Conditional Correlations of Equity Sector Return and Composite Index}

Figure 2 presents DCC-GARCH model of Engle (2002) and reveals the conditional correlation of the equity sectors return with the Malaysian composite index. The result highlights that the three sector indexes namely tin and mining, plantation and properties are weakly correlated with the composite index. At the beginning of 2000, the correlation among these indexes was very low and positive; afterward, it turned negative during 2000, which is a very attractive option for investors in these equity market. By contrast, the tin and mining sector have low correlation with the composite index, but the correlation increased at the beginning of 1999, after which it declined and even became negative at the end of 2018. Meanwhile, other sectors in this figure, the lines move up and down, which indicates that correlations among these indexes vary over time.

The results reveal that the correlation coefficients are the highest in trade and service sector. They vary between 0.297 for tin and mining sector to 0.947 for trade and services sector. The estimated correlation coefficients for the equity sectors are mostly significant. Since diversification potential is closely related to correlation levels, the evidence of the low crosssector correlations in equity market suggests that the inclusion of these sector may help reduce the risk of the portfolio.

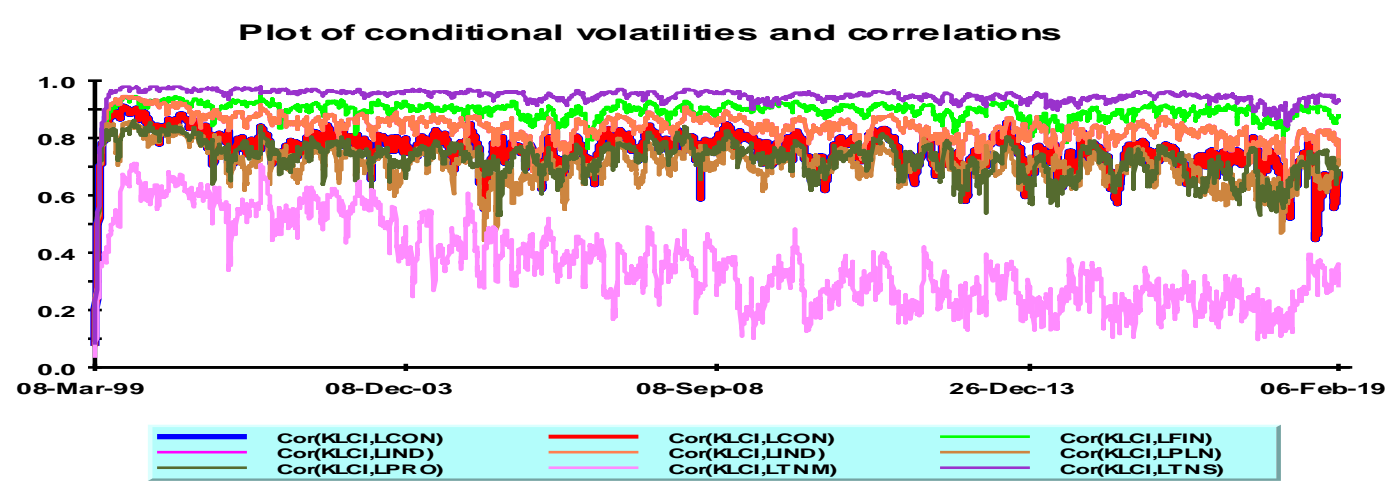

Figure 2. Conditional correlations of Malaysian equity sector return with composite index

\section{Conclusion}

The time-frequency domain analysis conducted in this paper can benefits from the portfolio diversification with the sectoral indices in Malaysia. A discussion on the dynamic relationship of return in Malaysian equities among comprehensive sector is rare in the field of finance. This study provides new insight into the co-movement and lead/lag relationship among Malaysian equities sectors from 1999 to 2019. To analyze the issue in detail, this study has distinguished the time-frequency relationship between sector return by using continuous wavelet approach and MGARCH-DCC.

The results of the study highlight that MGARCH-DCC illustrates higher co-movement between equity sector returns with the Malaysian composite index returns during the sample period. The finding reveals that majority of sectors strongly co-move. In terms of conditional correlation, the tin and mining, plantation and properties sectors are suitable for equity investors because of very low correlation. Moreover, the three sectors have negative conditional correlation with the composite index, which is a good sign for gaining 
diversification benefits for retail and institutional investors. Overall, the correlation of equity sector indexes are vary over time. After analyzing the developed bond market, Poynter et al. (2013) recommends that sectoral diversification benefits can be gained for investors with long-term investment horizons for their equity investments, which is similar to the findings of this study.

Further research should examine the co-movement of risk through the co-movement on a sectoral level. Although most of the previous studies have been focusing on the co-movement of country-level market indices, much less is known at sector levels. Therefore, a deeper understanding of risk and return behavior of such equity indices, and, in particular, their determinants, can help sustain the increasing interest of investors in the industry.

\section{Corresponding Author}

Aminah Shari, Labuan Faculty of International Finance, Universiti Malaysia Sabah Kampus Antarabangsa Labuan, Jalan Sungai Pagar, Labuan. Email: aminah83@ums.edu.my

\section{References}

Ahmad, W., Mishra, A. V., \& Daly, K. (2018). Heterogeneous dependence and dynamic hedging between sectors of BRIC and global markets. International Review of Financial Analysis, 59(June), 117-133. https://doi.org/10.1016/j.irfa.2018.07.005

Al-yahyaee, K. H., Mensi, W., Rehman, M. U., Vo, X. V., \& Kang, S. H. (2020). Do Islamic stocks outperform conventional stock sectors during normal and crisis periods? Extreme comovements and portfolio management analysis. Pacific-Basin Finance Journal, 101385. https://doi.org/10.1016/j.pacfin.2020.101385

Aliu, F., Pavelkova, D., \& Dehning, B. (2017). Portfolio risk-return analysis: The case of the automotive industry in the Czech Republic. Journal of International Studies, 10(4), 7283. https://doi.org/10.14254/2071-8330.2017/10-4/5

Barun, J. (2015). Gold, Oil, and Stocks: Dynamic Correlations. International Review of Economics and Finance. https://doi.org/10.1016/j.iref.2015.08.006

Bekaert, G., \& Harvey, C. R. (1995). Time-Varying Conditional World Market Integration. Journal of Finance, 50(2), 403-444.

Bouri, E., Gupta, R., Hosseini, S., \& Lau, C. K. M. (2018). Does global fear predict fear in BRICS stock markets? Evidence from a Bayesian Graphical Structural VAR model. Emerging Markets Review, 34, 124-142. https://doi.org/10.1016/j.ememar.2017.11.004

Candelon, B., Piplack, J., \& Straetmans, S. (2008). On measuring synchronization of bulls and bears: The case of East Asia. Journal of Banking and Finance. https://doi.org/10.1016/j.jbankfin.2007.08.003

Cho, J. W., Choi, J. H., Kim, T., \& Kim, W. (2016). Flight-to-quality and correlation between currency and stock returns. Journal of Banking and Finance, 62, 191-212. https://doi.org/10.1016/j.jbankfin.2014.09.003

Christoffersen, P., Errunza, V., Jacobs, K., \& Jin, X. (2014). Correlation dynamics and international diversification benefits. International Journal of Forecasting, 30(1), 807824. https://doi.org/10.1016/j.najef.2018.07.008

Dimic, N., Kiviaho, J., Piljak, V., \& Äijö, J. (2016). Impact of financial market uncertainty and macroeconomic factors on stock-bond correlation in emerging markets. Research in International Business and Finance, 36, 41-51.

https://doi.org/10.1016/j.ribaf.2015.09.001 
Faff, R. W., Hillier, D., \& Hillier, J. (2000). Time Varying Beta Risk: An Analysis of Alternative Modelling Techniques. Journal of Business Finance \& Accounting. https://doi.org/10.1111/1468-5957.00324

Greenwood, R. (2008). Excess comovement of stock returns: Evidence from cross-sectional variation in Nikkei 225 weights. Review of Financial Studies, 21(3), 1153-1186. https://doi.org/10.1093/rfs/hhm052

Jiang, Y., Yu, M., \& Hashmi, S. M. (2017). The financial crisis and co-movement of global stock markets-a case of six major economies. Sustainability (Switzerland), 9(2), 1-18. https://doi.org/10.3390/su9020260

Kim, M. H., \& Sun, L. (2017). Dynamic conditional correlations between Chinese sector returns and the S\&P 500 index: An interpretation based on investment shocks. International Review of Economics and Finance, 48(November 2016), 309-325. https://doi.org/10.1016/j.iref.2016.12.014

Marfatia, H. A. (2017). A fresh look at integration of risks in the international stock markets: A wavelet approach. Review of Financial Economics, 34(1), 33-49. https://doi.org/10.1016/j.rfe.2017.07.003

Mazouz, K., Mohamed, A., \& Saadouni, B. (2016). Stock return comovement around the Dow Jones Islamic Market World Index revisions. Journal of Economic Behavior and Organization, 132, 50-62. https://doi.org/10.1016/j.jebo.2016.05.011

Mensah, J. O., \& Premaratne, G. (2017). Dependence patterns among Asian banking sector stocks: A copula approach. Research in International Business and Finance, 41(April), 516-546. https://doi.org/10.1016/j.ribaf.2017.05.001

Mensi, W., Hammoudeh, S., Al-Jarrah, I. M. W., Sensoy, A., \& Kang, S. H. (2017). Dynamic risk spillovers between gold, oil prices and conventional, sustainability and Islamic equity aggregates and sectors with portfolio implications. Energy Economics, 67, 454-475. https://doi.org/10.1016/j.eneco.2017.08.031

Mensi, W., Hammoudeh, S., \& Kang, S. H. (2017). Risk spillovers and portfolio management between developed and BRICS stock markets. North American Journal of Economics and Finance, 41, 133-155. https://doi.org/10.1016/j.najef.2017.03.006

Minovi, J., \& Simeunovi, I. (2002). Applying MGARCH Models in Finance. Udc.

Dahir, M. A., Mahat, F., Ab Razak, N. H., \& Bany-Ariffin, A. N. (2018). Revisiting the dynamic relationship between exchange rates and stock prices in BRICS countries: A wavelet analysis. Borsa Istanbul Review, 18(2), 101-113.

https://doi.org/10.1016/j.bir.2017.10.001

Poynter, J. G., Winder, J. P., \& Tai, T. (2013). An analysis of co-movements in industrial sector indices over the last 30 years. Review of Quantitative Finance and Accounting, 44(1), 6988. https://doi.org/10.1007/s11156-013-0399-z

Sun, Q., \& Xu, W. (2018). Wavelet analysis of the co-movement and lead-lag effect among multi-markets. Physica A: Statistical Mechanics and Its Applications, 512, 489-499. https://doi.org/10.1016/j.physa.2018.08.102 